\title{
SEISMIC DAMAGE EVALUATION OF REINFORCED CONCRETE SLIT WALLS
}

\author{
SERGIU A. BAETU, ALEX H. BARBAT, IOAN P. CIONGRADI
}

\section{Introduction}

Reinforced concrete walls are structural elements used in multi-story buildings in earthquake prone countries like Romania, Turkey, Chile, Mexico, China, Japan, USA, Peru etc., because they have a high capacity of resisting lateral loads. Nevertheless, it is important to maintain the seismic vulnerability of buildings made with such walls within reasonable limits (Barbat el al, 2006, Barbat et al. 2010), providing them sufficient ductility to avoid their brittle failure under the action of strong seismic loads. When a structure is subjected to strong earthquakes, it is necessary to assure, for economical design reasons, inelastic deformations without the failure of the building; this is because the design of buildings based on performance criteria takes into account the dissipation of seismic energy accumulated in the structure. The fact is that, in a tall structural wall, plastic hinges appear only at the base of the wall and the rest of the wall remains undamaged. There is an alternative solution which overcomes this drawback, consisting of creating a slit zone with short connections introduced into the wall structure. The slits are complete breaks in concrete and reinforcements in order to change the solid structural reinforced concrete wall to a series of flexural wall-columns. In this way, the deflection capacity of the wall is larger, adequate to be used in high-rise buildings. This solution assures small lateral deflections of the buildings during minor earthquakes and a large, beyond the elastic limit, storey displacement during major earthquakes. The solution proposed in this paper-structural reinforced concrete slit walls- changes the behaviour of a the solid wall and provides to the structure more ductility, energy dissipation and adequate crack patterns (see Figure 1).

In Romania, many multi-storey buildings with structural walls have suffered serious damages during high intensity earthquakes. For instance in Bucharest, during the 1977 Vrancea (Romania) earthquake, these buildings showed a high seismic vulnerability: one building with cast-in situ reinforced concrete structural walls totally collapsed, seven other buildings suffered partial collapse, 19 were significantly damaged and 72 were moderately damaged. Some of the reasons of the collapses were the inadequate wall density, the inadequate amount and detailing of the wall reinforcement and the lack of confinement in the boundary elements (Bostenaru and Sandu, 2002). In Romania, these types of structural walls are not currently used as a solution for dissipating the energy induced by earthquakes in high-rises buildings but we consider that they could be successfully used in the future. The main reason of this statement is the presence of soft soils that represent a major problem in many areas of Romania, together with the deep-focus earthquakes, leading to soil periods higher than $1 \mathrm{~s}$. In the case of soft soil and stiff building, the soil will absorb the seismic energy through deformations that can cause the overturning of the building (Marin and Roman, 2010). The implementation of slit walls in high-rise buildings produces a sudden decrease of the stiffness at a high seismic threat and the natural period of the building increases avoiding, in this way, resonance. The sudden decrease of the stiffness is due to the degradation of the short connections of the slit walls. With this solution, the seismic demands can be significantly reduced and an economical design can be reached.

The first precast slit panel was patented by Professor K. Muto, in Japan, in 1973 (Fig. 1a) (Muto et al., 1973). This is the first energy dissipation system used in Japan. This solution consisted of precast RC vertical strips introduced in the steel frames. Other solutions of slit walls have been proposed by Chinese, Korean, Iranian and Russian researchers. The Korean researchers proposed a slit panel used for reinforced concrete framed buildings in which strips are anchored into the beams (Fig. 1b) (Liou and Sheu, 1998). These types of panels were experimentally tested at four types of lateral loads: monotonic loading, repeated loading, reverse cyclic loading and random cyclic loading. From the experimental tests, it was found that the failure mechanism is changed through this solution from shear to flexural. 
A cast-in situ structural slit wall with a slit zone with short connections or inserted rubber belts (figures 1d and 1e) was proposed in China (Kwan et al., 1999, Lu and Xu, 2000, Lu and Huanjun, 2002). For the case with rubber belts inserted into slit zone experimental tests were done on the shaking table with the acceleration record of El Centro N-S (1940) as the input earthquake wave. The conclusion was that the slit wall has better energy dissipation capacity than an ordinary structural wall. For the walls with short connections inserted into the slit zone, numerical nonlinear dynamic analyses were done considering the walls with a linear behaviour and the short connections with nonlinear behaviour. This slit wall was also numerically simulated with the column frame analogy. The short connections were evaluated using the softened truss model theory for the static behaviour and from the monotonic load-deflection curve; a hysteretic model is created using some hysteretic rules from other experimental tests on short beams from the literature. A cast-in situ reinforced concrete slit wall with a variable number of slits over the height (Fig. 1f) was proposed in Iran (Sabouri and Ziyaeifar, 2009, Labafzadeh and Ziyaeifar, 2008) and static and dynamic nonlinear analyses with finite element were done on these elements. A precast panel with concrete strips assembled by post-stressing (Fig. 1c) has been patented in Russia (Pavlik and Vasionkin, 1976. These solutions have been used to construct high-rises buildings up to 38 floors in Japan (Aoyama, 2005) and China (Lu and Huanjun, 2002), buildings that behaved very well during recent seismic events. The slab in these types of buildings can be cast-in situ or precast, and the structural walls are positioned at the border of the building or into the core, in order to reduce the influence of the slab stiffness.

Unlike in other studies on slit walls (Kwan et al., 1999), which perform a dynamic analysis focused only on the nonlinear behaviour of the short connections, in the present article we take into consideration the nonlinear behaviour of both the wall and the connections and our main objective is to evaluate numerically the damage of the slit wall in comparison with the damage of a solid wall.
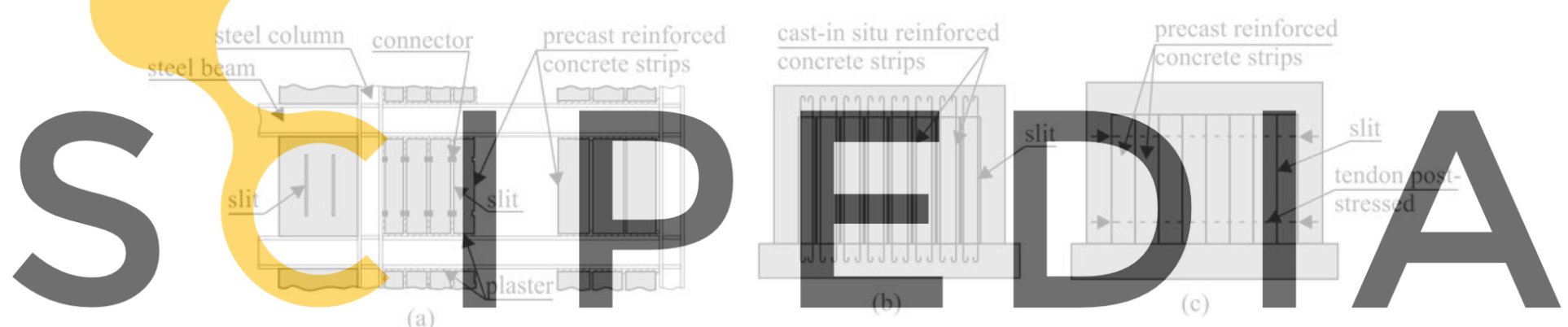

Register for free at https//www.scipedia.com to download the version without the watermark

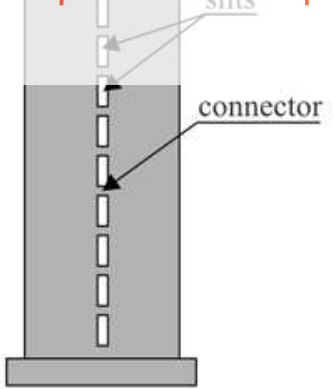

(d)

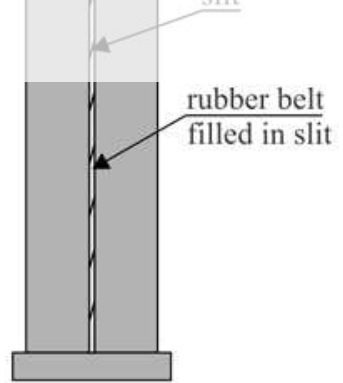

(e)

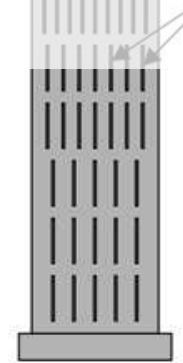

(f)

Fig. 1. Slit panels and walls: (a) precast slit panel with strips introduced in steel frames (Muto et al., 1973), (b) slit panel with strips anchored in beams (Liou and Sheu, 1998), (c) precast panel with strips assembled by post-stressing (Pavlik and Vasionkin, 1976), (d) cast-in situ slit wall with a slit zone with short connections (Kwan et al., 1999), (e) cast-in situ slit wall with rubber belts inserted in slit zone ( $\mathrm{Lu}$ and $\mathrm{Wu}, 2000)$ and (f) cast-in situ reinforced concrete slit walls with a variable number of slits on height (Sabouri and Ziyaeifar, 2009)

The purpose of this article is to develop a computational model allowing to study the nonlinear dynamic behaviour of reinforced concrete slit walls with short connections and to evaluate the possibility of its use in multi-storey buildings in seismic areas. A case study corresponding to a 20 levels building designed for a seismic area with a dual reinforcement is analysed and discussed. A structural wall is extracted from this building and its detailed nonlinear structural analysis is performed. The same wall is then modified into a slit wall with short connections, in order to study the improvement if its behaviour when compared with that 
of the original wall. A dynamic nonlinear analysis of both walls is performed with the SAP2000 code using the layered model. The hysteretic behaviour of the short connections is simulated by performing a monotonic static analysis in the finite element code ANSYS 12; the shear force-deformation curve obtained thus is introduced in structural model analysed in SAP2000. We used this procedure because ANSYS 12 allows calculating the behaviour of short connections with a realistic finite element model able to handle complex geometries and to describe precisely the complex stress state and the cracking pattern. The dynamic analysis of the walls allowed to calculate the dissipated hysteretic energy of the studied walls and to obtain the global seismic damage index of Park\&Ang (1985). The study of the entire building with slit walls is out of the scope of this article. Our objective is to develop the computational model for a single slit wall, to perform analyses on a set of relevant cases illustrating the application of the model and to obtain conclusions on the seismic behavior of slit walls useful for future research.

\section{The computational model}

The computational model for a reinforced concrete slit wall with short connections is described in this section. The materials used in the model are first defined. Computational model of the structural wall, based on a layered model, is then proposed. Finally, the hysteretic behaviour model for the short connections was developed and calibrated. With the computational model obtained for the slit wall, we performed dynamic analyses in order to illustrate the better seismic behaviour of the slit wall, using as a criterion the global seismic damage index of Park\&Ang.

\subsection{Material definition}

The characteristics of the concrete and steel used in the nonlinear dynamic analysis for modelling the reinforced concrete structural walls are discussed in this section. The concrete is the C32/40. For defining the layers of the confined and the unconfined concrete and of the steel, it is necessary to introduce their
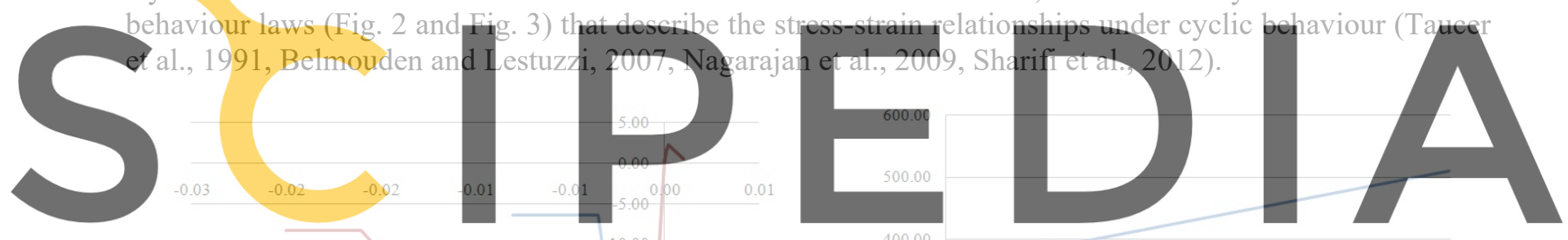

Register 声or free at https//www.scipedia.com to download the version without the watermark

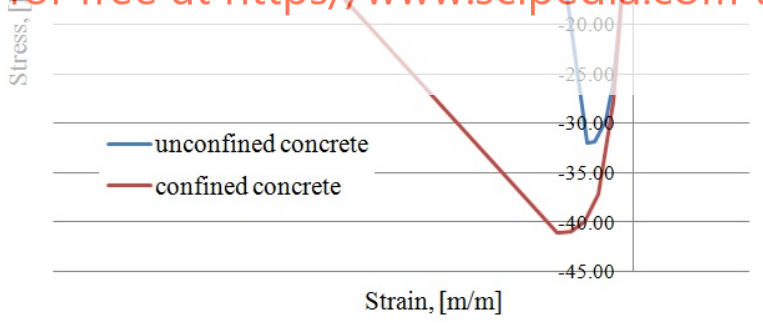

Fig. 2. The behaviour law of confined and unconfined concrete

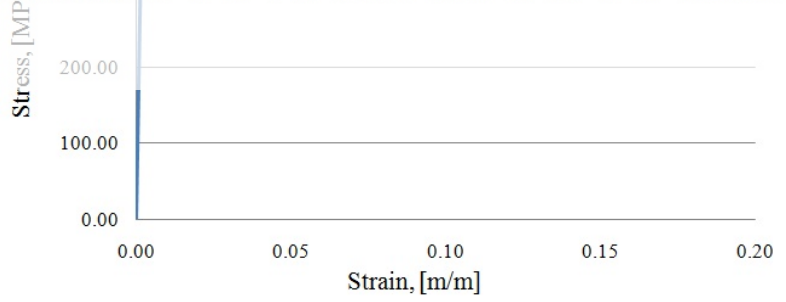

Fig. 3. The behaviour law of steel

The monotonic envelope curve of concrete follows the Takeda hysteretic model and the stress-strain curve of the steel follows the kinematic hysteretic model, both of them being predefined in SAP2000. The multilinear isotropic stress-strain curve for unconfined concrete is computed with the equations proposed by Desayi and Krishnan in 1964 (Kachlakev et al., 2001) and, for confined concrete, the strength and deformations have been increased according to SR EN 1992-1-1:2004 (SR EN 1992-1-1:2004).

\subsection{Description of the layered shell element for the structural walls analysis}

The analysis of damage due to seismic actions requires the use of efficient structural models capable of describing the actual structural behaviour, like the layered shell model which is useful in performing nonlinear dynamic analyses of reinforced concrete structural walls. The reinforced concrete wall is subdivided into parallel layers, some of them corresponding to concrete and others to the reinforcement. This 
model, used to simulate the nonlinear behaviour of reinforced concrete structural walls, is based on the principles of the mechanics of composite materials and is able to describe bending in the median plane or perpendicular to the median plane, as well as simultaneous bending and shear in the median plane. The element, shown in Fig.4, is made of several layers with different thickness and different properties are assigned to the layers. The reinforcement bars are inserted within one or more layers. During the finite element calculation, the axial strain and curvature of the middle layer can be obtained in one element and the strains and the curvatures of the other layers can be calculated. The corresponding stresses are calculated through the constitutive relations of the material assigned to the layers and, thus, the structural performance of the shear wall can be directly connected with the material constitutive law.
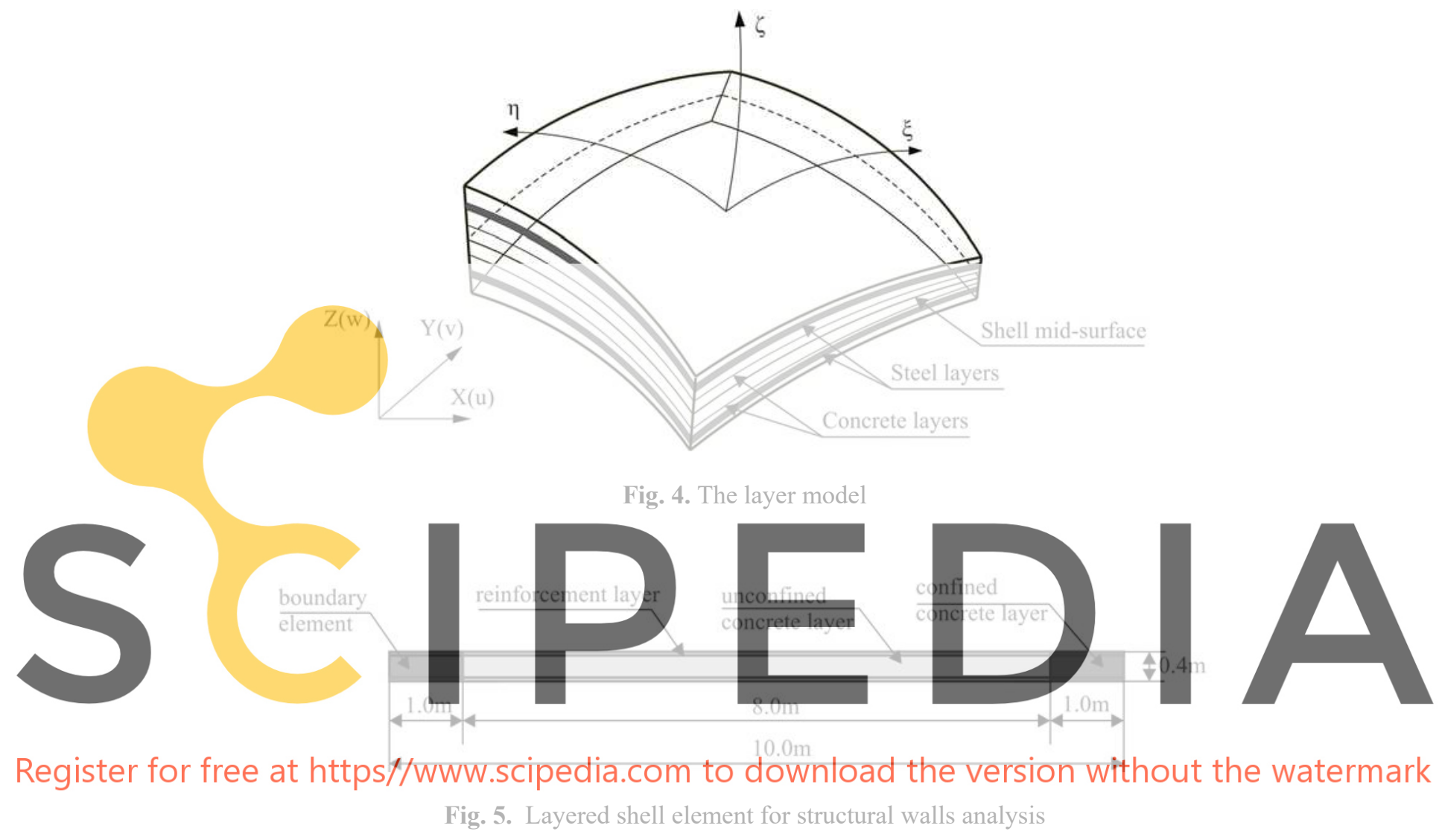

The reinforcements disposed in different directions can be introduced in a single layer. If the amount of the steel reinforcement distributed in longitudinal and transversal directions of the concrete is the same, the layer of steel can be introduced as isotropic. But, if the quantities of steel according to the two directions are different, a reinforcement layer with two orthotropic main axes has to be used (Miao et al., 2006, Baetu and Ciongradi, 2011).

We performed the nonlinear analyses of RC structural walls studied in this article by using the SAP2000v14 software and the layered shell model existing in this code. The dynamic nonlinear analysis was done in SAP2000 software using the layered shell model which considers the interaction between bending and shear in the performed nonlinear analysis. Five layers have been defined, one corresponding to the confined and unconfined concrete in the wall and its boundaries and four corresponding to the reinforcement in the horizontal and vertical directions on both sides of the wall section (Fig. 5) (Sap2000 V14 Help).

\subsection{Finite element analysis in ANSYS 12 of the short connection}

The definition of the structural model for short connections under cyclic loading can be developed in the following steps:

- Definition of a monotonic curve - the cyclic envelope can be coincident with the monotonic one;

- Definition of the unloading rules - the unloading branch can be linear; 
- Definition of the re-loading rules - the re-loading branch may follow complex rules considering slip and pinching.

A monotonic curve for the short connection can be defined experimentally or by using the finite element method. The last possibility was selected in this case by using the computer program ANSYS 12 because it can simulate reinforced concrete elements with a very good accuracy, the results being close to the experimental ones (Kheyroddin and Naderpour, 2008, Raongjant and Jing, 2008).

The seismic nonlinear analysis of the reinforced concrete slit wall with short connections requires their hysteretic behaviour based on an adequate constitutive hysteretic model. The short connections have been introduced in SAP2000 (Fig. 6) as link elements with multi-linear pivot hysteretic plasticity property (Lepage et al., 2006), because this hysteretic model is suitable for reinforced concrete members dominated shear. This model, which is capable to simulate very easily the pinching effect, is similar to the multi-linear constitutive model of Takeda but has additional parameters which control the degradation of the hysteretic behaviour. In this model the loading and reloading are directed to specific points named pivot points (Fig. 7) (Sap2000 V14 Help). The model is governed by three simple rules: (1) loading and reloading in quadrants $\mathrm{Q}_{1}$ and $\mathrm{Q}_{3}$ is directed away from point $\mathrm{P}_{1}$ or toward point $\mathrm{P}_{3}$; (2) loading in quadrants $\mathrm{Q}_{2}$ and $\mathrm{Q}_{4}$ is directed toward point $\mathrm{PP}_{2}$ and point $\mathrm{PP}_{4}$; and (3) unloading in quadrants $\mathrm{Q}_{2}$ and $\mathrm{Q}_{4}$ is directed away from points $\mathrm{P}_{2}$ and $\mathrm{P}_{4}$. The backbone curve used for positive and negative loading is shown in Fig. 7.
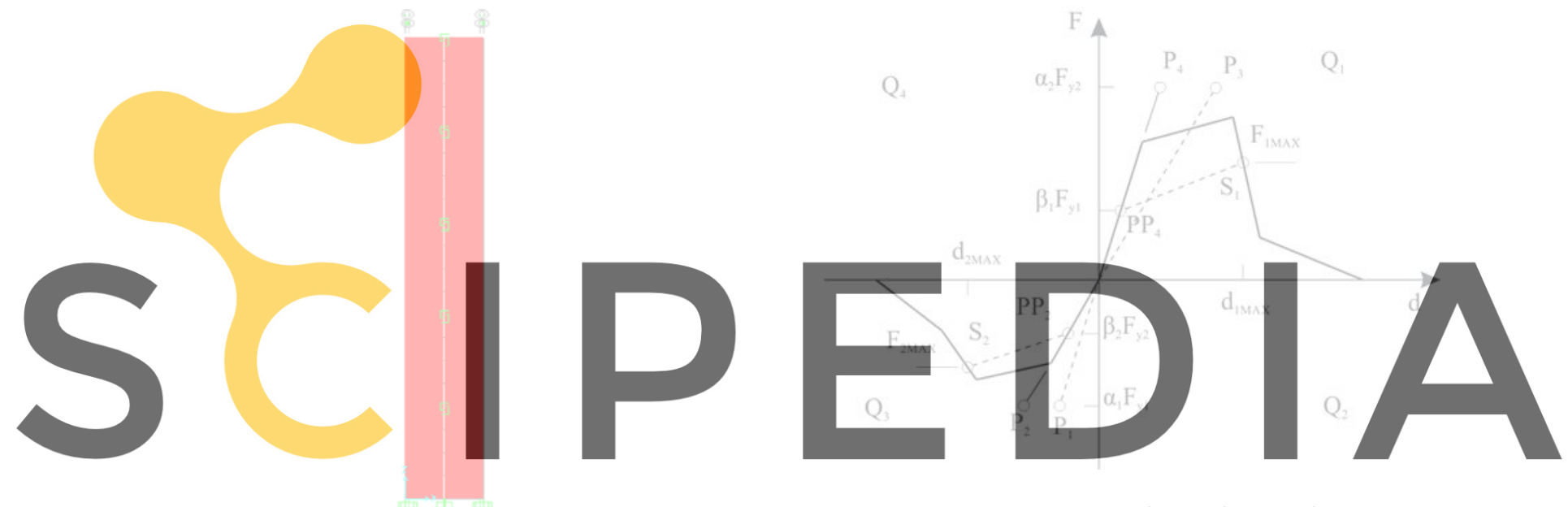

\section{Register for free at https//www.scipedia.com to download Fig. 7 Strength envelping and the watermark Fig. 6. Slit wall with five short connections analyzed in SAP2000

The first branch of the curve of Fig. 7 describes the monotonic behaviour of the short connections implemented into the slit wall proposed for analysis and the second branch represents the strength degradation. The primary pivot points $\mathrm{P}_{1}$ and $\mathrm{P}_{4}$ control the amount of softening expected when displacement increases, using the parameters $\alpha_{1}$ and $\alpha_{2}$, and the pinching pivot points $\mathrm{PP}_{2}$ and $\mathrm{PP}_{4}$ fix the degree of pinching following a load reversal, through parameters $\beta_{1}$ and $\beta_{2}$. The response follows the strength envelope as long as no displacement reversal occurs. Once the yielding displacement is exceeded in either direction, a modified strength envelope is defined by the lines joining $\mathrm{PP}_{4}$ to $\mathrm{S}_{1}$ and $\mathrm{PP}_{2}$ to $\mathrm{S}_{2}$ (Dowell et al., 1998, Costa, 2006, Pasticier et al., 2008).

The hysteretic force-displacement curve with stiffness and strength degradation and pinching effect was defined in Fig. 9. The construction of this hysteretic curve begins with the monotonic forcedisplacement curve of a short connection (Fig. 10), obtained with the finite element code ANSYS 12 and by using the pivot hysteretic rules for loading and unloading explained in the previous two paragraphs. The hysteretic parameters required are extracted from the experimental static (Fig. 8) and from cyclic analyses for short beams dominated by shear (Kwan et al., 1999, Gedik et al., 2011, Zhao et al., 2004). These test results show that the beams fail brittle directly from the elastic range and after the peak load, a ductile behaviour is observed, if the beam is well reinforced. It was proved that in short deep beams having shear span to depth ratio less than 1, the compressive shear failure occurs with spalling of concrete along the compression struts (Gedik et al., 2011). In the experimental test presented in fig. 8 was analyzed a deep beam with depth ratio of 0.5 . 
Fig. 9 describes the hysteretic behaviour of a reinforced concrete short beam, where $\mathrm{k}$ is the initial stiffness, $F_{y}$ is the yield force, $d_{y}$ is the yield displacement and $\mu$ is the ductility. The ductility was approximated to 3 from the experimental static curve shown in Fig. 8, considering the displacement of $2.5 \mathrm{~mm}$ at 0.8 of the yielding force $(0.8 * 300=240 \mathrm{kN})$ and the yield displacement of approximately $0.8 \mathrm{~mm}$.
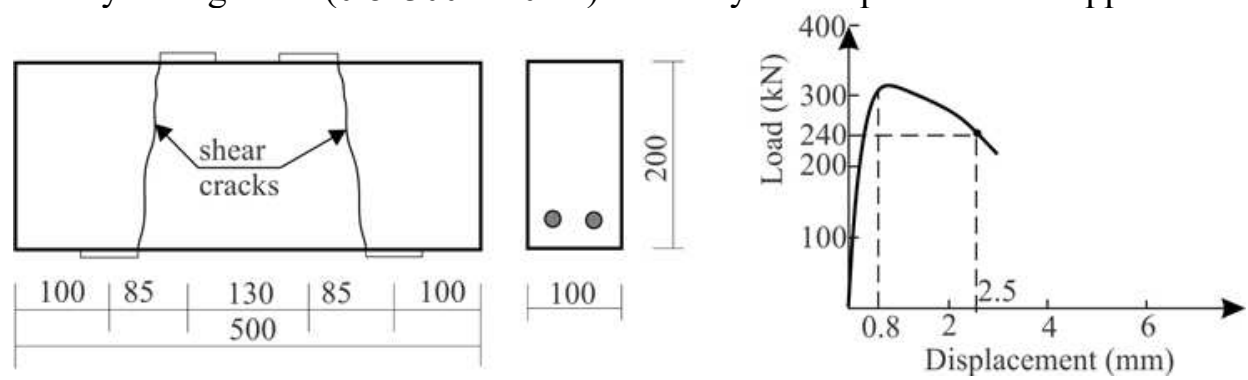

Fig. 8- Static experimental analysis for a short beam
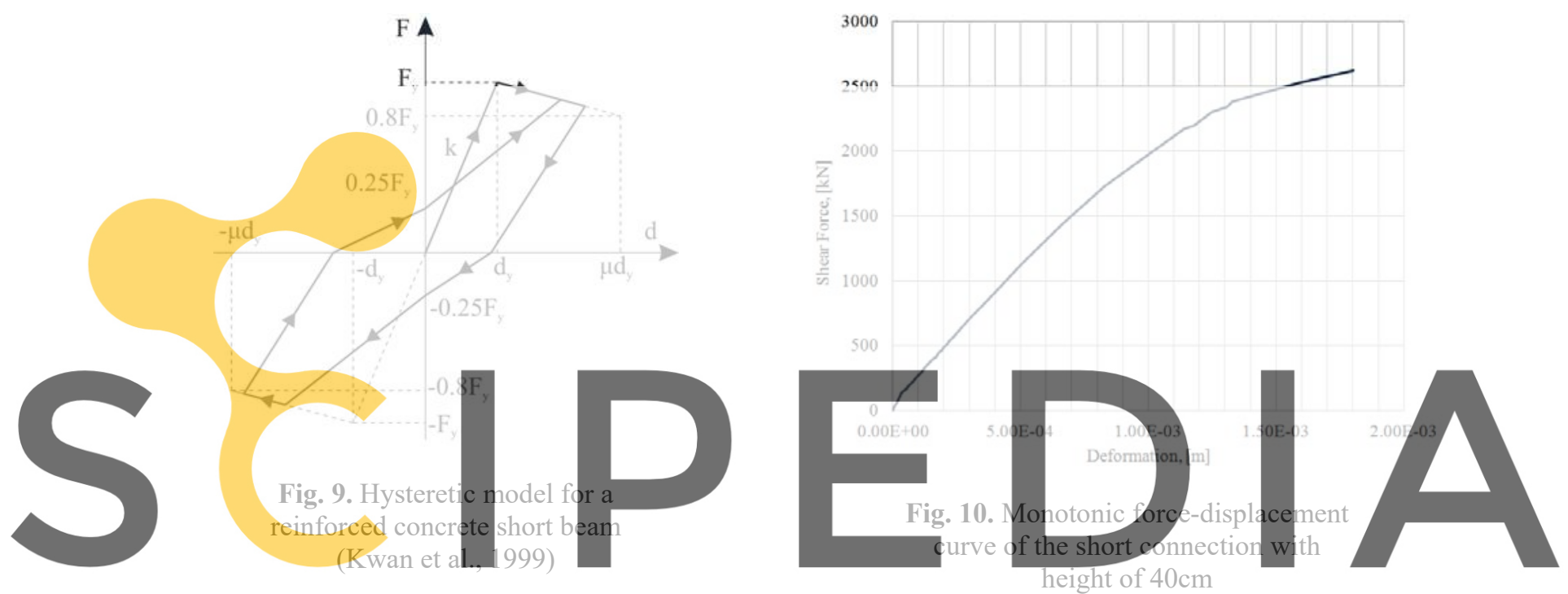

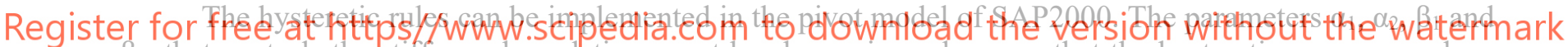
$\beta_{2}$, that controls the stiffness degradation, must be chosen in such a way that the hysteretic curve reproduce the rules set for the reinforced concrete short beams: $\alpha_{1}=\alpha_{2}=1, \beta_{1}=\beta_{2}=0.25$.

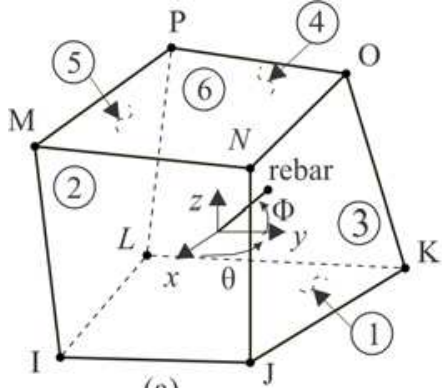

(a)

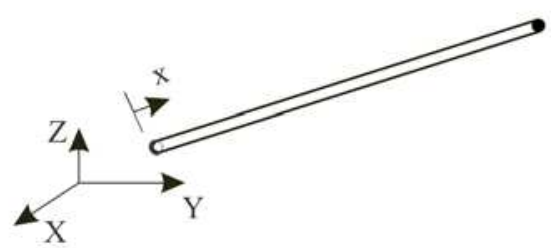

(b)

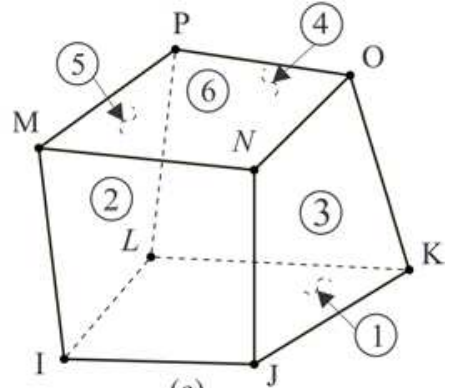

(c)

Fig. 11. Finite elements used in analysis: (a) Solid 65 for concrete, (b) Link 8 for rebars and (c) Solid 45 for steel plate

In the analysis of the short connection performed with the ANSYS 12 computer program, the finite element used for concrete is Solid 65 with cubic shape and the dimension of $50 \mathrm{~mm}$ (Fig. 11a). Solid 65 elements are capable of plastic deformation, cracking in three orthogonal directions, and crushing. The loading is applied in the $y$ direction through a steel plate in order to prevent stress concentrations. The steel plate is meshed with finite element Solid 45 (Fig. 11c) with the same dimensions as the concrete is. The reinforcement bars may be included in the finite element model in two ways as a discrete model (individual bars) (Fig. 11b) or as a smeared model (Fig. 11a). In this case, the rebars were modelled by using separate 
element called Link 8, a 3-D spar element with the length of $50 \mathrm{~mm}$ (Greeshma et al., 2011, Raongjant and Jing, 2008, Terec et al., 2010, 2006, ANSYS 12/2009).

The short connections are the key elements of reinforced concrete structural slit walls, in the analysis of which it is very important to consider the nonlinear behaviour of the short connections. Therefore, we extracted from the slit wall a short connection with $1 \mathrm{~m}$ in length and $2 \mathrm{~m}$ in height on each side (Fig. 12). The structural part on the left is fully restrained on all edges and the right zone is restrained in the $x$ direction on the edge parallel with the $y$ axis, with the purpose of blocking the rotations, being thus the short connection subjected only to pure shear. In this analysis, a connection with a height of $40 \mathrm{~cm}$, reinforced with $6 \varnothing 12$, was chosen. The corresponding zones of the wall were reinforced, the same as the wall, with vertical rebars $\varnothing 14 / 15$ and horizontal rebars $\varnothing 10 / 15$. The concrete used in the analysis is C32/40, the same which has been used in the analyses performed with SAP2000, and the behaviour law of the materials is the same. The results of the finite element analysis show that the short connections are dominated by high shear forces, as it can be seen in Fig. 10, being the ultimate shear force $2623 \mathrm{kN}$ and the ultimate deformation 1.8 $\mathrm{mm}$. From these results, it can be concluded that a short connection has a brittle failure, with small inelastic deformations. Fig. 13 shows the cracking pattern, with shear cracks in the short connection, with crushing of concrete in the left zone down and in the right zone up and with cracks due to tension stresses in the left zone up and in the right zone down.
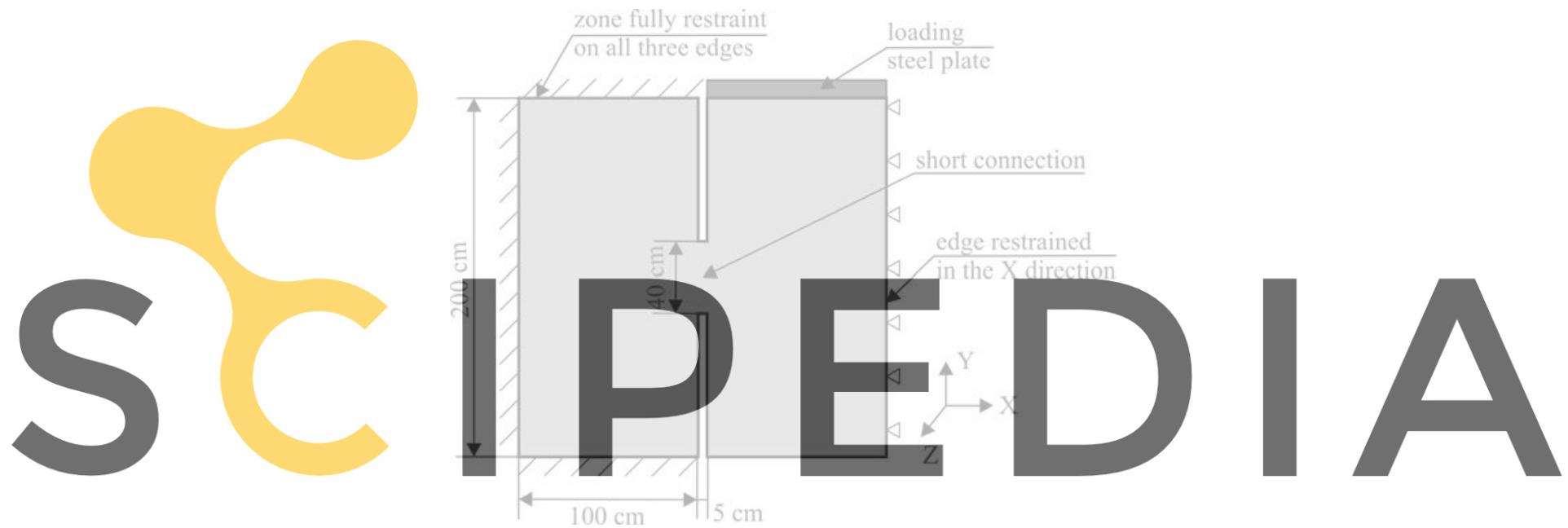

Register for free at https//www.scipedia.Gemotond ewaloa de thet doersion without the watermark

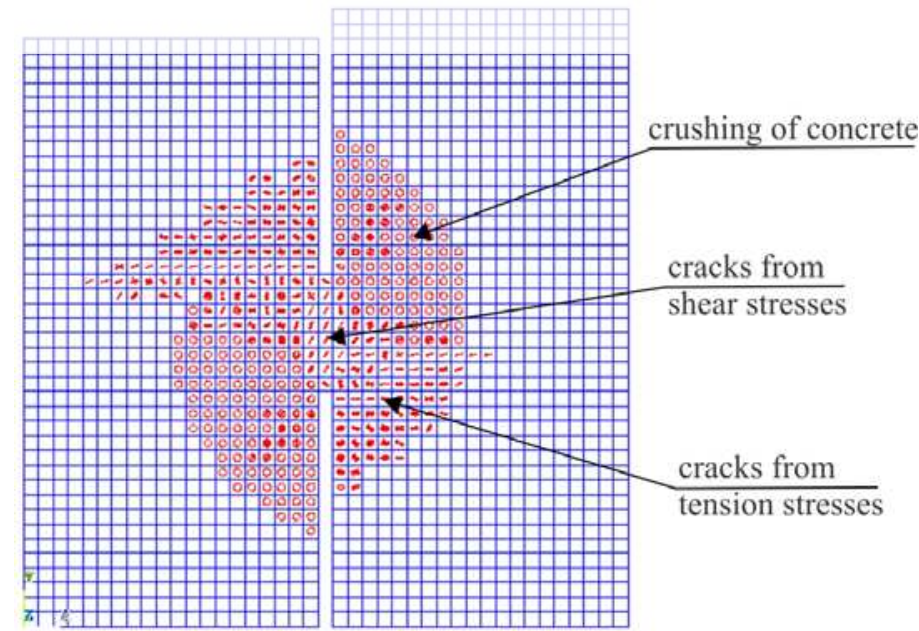

Fig. 13. The cracking pattern of the short connection

2.4 Description of the damage index of Park\&Ang

There are numerous damage indices proposed in the literature, based on various conceptual frameworks. The damage index of Park\&Ang is nowadays widely used in seismic damage evaluation because of its simplicity and robustness. This damage model served as a baseline for many researchers and was calibrated on the basis of structural degradations observed in experimental test of buildings. The 
damage model was also calibrated after damages and collapses observed in nine reinforced concrete buildings during the 1971 San Fernando earthquake in California, the 1978 Miyagiken-Oki earthquake in Japan and others severe earthquakes. Structural damage is considered as a linear combination between damage due to deformations and due to dissipated hysteretic energy at repeated cyclic loading. The damage index is calculated with the following relation:

$$
D I_{P \& A}=\frac{\delta_{m}}{\delta_{u}}+\frac{\beta}{\delta_{u} P_{y}} \int d E_{h}
$$

where: $\delta_{m}$ is the maximum deformation of the wall under seismic loading,

$\delta_{u}$ is the ultimate deformation of the wall under monotonic static loading,

$P_{y}$ is the yield strength from the idealized curve,

$\int d E_{h}$ is the incremental hysteretic energy dissipated during the seismic loading,

$\beta$ is the constant parameter of the model (usually, it has a value of 0.1 ).

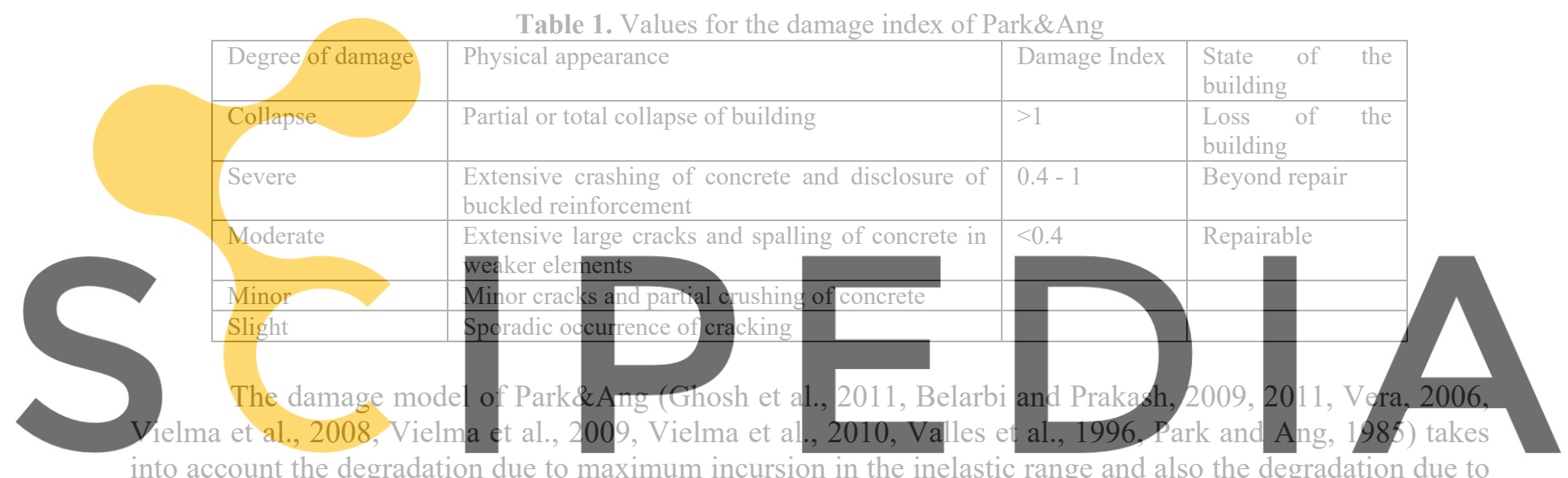

into account the degradation due to maximum incursion in the inelastic range and also the degradation due to cyclic deformations. An experiment conducted at Universidad Técnica Federico Santa Maria from Chile on

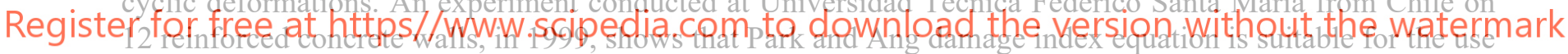

in slender RC walls, and the parameter $\beta$ is very close to the theoretical one. This study reveals also that there are some limitations for the walls dominated by shear and in these cases the parameter $\beta$ is not recommended to be calculated with the relation proposed by Park and Ang (Vera, 2006). In the case of slit walls this method is even better to be used due to the fact that the walls become very slender after the short connections fail. Park and Reinhorn (1988) give a relation for the empirical parameter $\beta$ and also for the ultimate displacement obtained by Hiroshawa. They tested 402 beam and columns and 67 shear walls in order to obtain empirical equations. The value chosen for the parameter $\beta$ for the studied structural walls is 0.1. This value was chosen from the experimental tests of Vera (2006) on 12 reinforced concrete walls. The direct application of the damage model on a structural element, a story or a building, requires determining the ultimate deformations of the corresponding element, story or building. Table 1 shows the values of the damage index correlated with different levels of damage.

\subsection{The idealized parameters of the strength envelope}

In order to calculate two of the parameters needed in the estimation of the damage index, the ultimate displacement and the yielding force of the proposed structural slit wall, a cyclic analysis has been done. This type of analysis has been chosen because the monotonic static analysis does not provide good results in the case of slit walls. A push-over analysis was also done by using SAP2000 code, but the obtained results were inconclusive because, when using this code, the slit wall fails when the short connections fail while the solid wall fails for the displacement imposed by the user into the software; thus, these results does not allow establishing the actual ultimate displacement of the walls. In reality, the failure of the short connection causes strength degradation and a large displacement of the wall. We decided to capture the strength degradation by performing a cyclic analysis with the computer program ANSYS 12 (Baetu and Ciongradi, 
2012). We need herein only the strength envelope (figures 14 and 15), in order to extract the yielding force, and the ultimate displacement, required to calculate the damage index of Park\&Ang. They are obtained by replacing each strength envelope with an idealized curve. The case of slit walls is a special one because the strength envelope has strength degradation and the idealized curve has to be tri-linear and, therefore, it was developed according to FEMA 440 (FEMA 440). The sum of the areas enclosed between the curve and the idealized curve must be zero (Fig. 14 and 15).

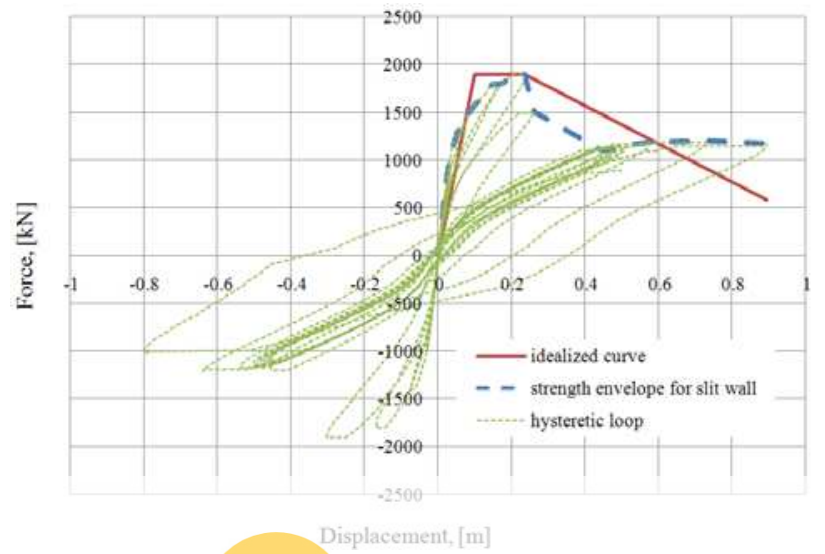

Fig. 14. Strength envelope and idealized curve for slit wall proposed [49]

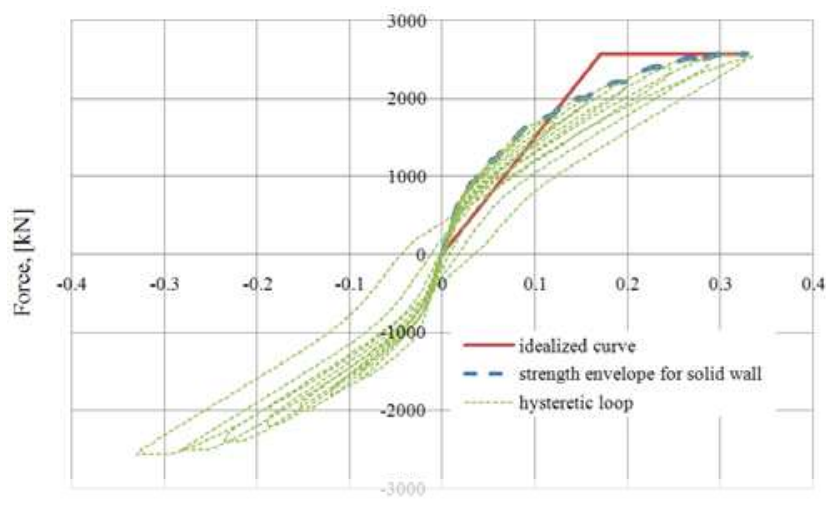

Displacement, [m]

Fig. 15. Strength envelope and idealized curve for solid wall proposed [49]

Comparing the strength envelope of the slit wall (Fig. 14) with that of the solid wall (Fig. 15), we can observe that the solid wall fails at a higher lateral force, of $2565 \mathrm{kN}$, and at lower displacement, $32.8 \mathrm{~cm}$,

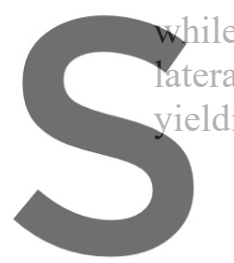

ateral force of the slit wall is

elding force, the yielding di
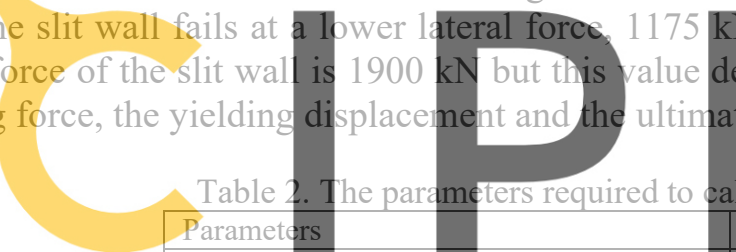

Yielding displacement, $[\mathrm{cm}]$

Yielding force, $[\mathrm{kN}]$

$\mathrm{N}$, and a higher
ecreases after the
te displacements
alculate the Park\& A
Slit wall

10

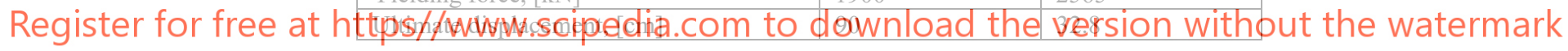

Two more parameters are needed to calculate the Park\&Ang damage index, that is, the maximum deformation of the wall under seismic loading and the incremental hysteretic energy dissipated during the earthquake. These parameters are calculated by means of a seismic analysis performed in SAP2000 with layered model described above.

\section{Seismic analysis of a dissipative wall from a multi-storey building}

3.1 Description of the studied structure

The case study considers a multi-storey building in a seismic area from which a reinforced concrete structural wall is isolated. The building is located in the city of Iaşi, Romania, which has the following site characteristics: design ground acceleration $\mathrm{a}_{\mathrm{g}}=0.2 \mathrm{~g}$, control period $\mathrm{T}_{\mathrm{c}}=0.7 \mathrm{~s}$, ductility class $\mathrm{H}$, importance factor $\gamma_{\mathrm{I}}=1$ (P100-1/2006). The building has dual reinforced concrete structure and regular form in plan and elevation. The seismic lateral loads applied upon the building are absorbed by the concrete core and, in the short direction, by the border walls. It has 20 levels with a height of $3 \mathrm{~m}$ each. In plan, the building has $31 \mathrm{~m}$ in length and $21 \mathrm{~m}$ in width (Fig. 16). The concrete used in the analysis is C32/40. The fundamental period of the structure is $T_{1}=1.077 \mathrm{~s}$. The dimensions of the cross section of the columns are $100 \times 100 \mathrm{~cm}$, the slab thickness is of $15 \mathrm{~cm}$ and in the center the building has two reinforced concrete cores for stairs and elevator with the dimensions $4 \times 7 \mathrm{~m}$ and $4 \times 4 \mathrm{~m}$, respectively; all the walls have the thickness of $40 \mathrm{~cm}$. The study is focused on the boundary wall with a length of $10 \mathrm{~m}$ (Fig. 17). The design analysis was performed with the computer program SAP2000 (Fig. 19) with which a thickness of the wall of $40 \mathrm{~cm}$ was obtained; the wall is reinforced with vertical bars $ø 14 / 15$ (rebars with diameter of $14 \mathrm{~mm}$ disposed at a distance of $15 \mathrm{~cm}$ ) and horizontal bars $ø 10 / 15$ (rebars with diameter of $10 \mathrm{~mm}$ disposed at a distance of $15 \mathrm{~cm}$ ) (CR 2-1-1.1-2005, 
Baetu et al., 2010). The seismic analysis of the building was done using the response spectrum method, and in the standards it is also recommended to perform a pushover analysis in order to determine the failure mechanism of the building. P-delta effects are neglected in this study. The dimension and the reinforcement of the boundary element, which are presented in Fig. 18, were designed according to the Romanian standard CR 2-1-1.1-2005, in order to reach a high level of ductility during a seismic event. There are five connections along the wall height disposed at equal length of $12 \mathrm{~m}$. The height of each connection is $0.40 \mathrm{~m}$ and the thickness of the slit is $5 \mathrm{~cm}$. Comparative analyses were conducted on the slit wall and on the solid wall.

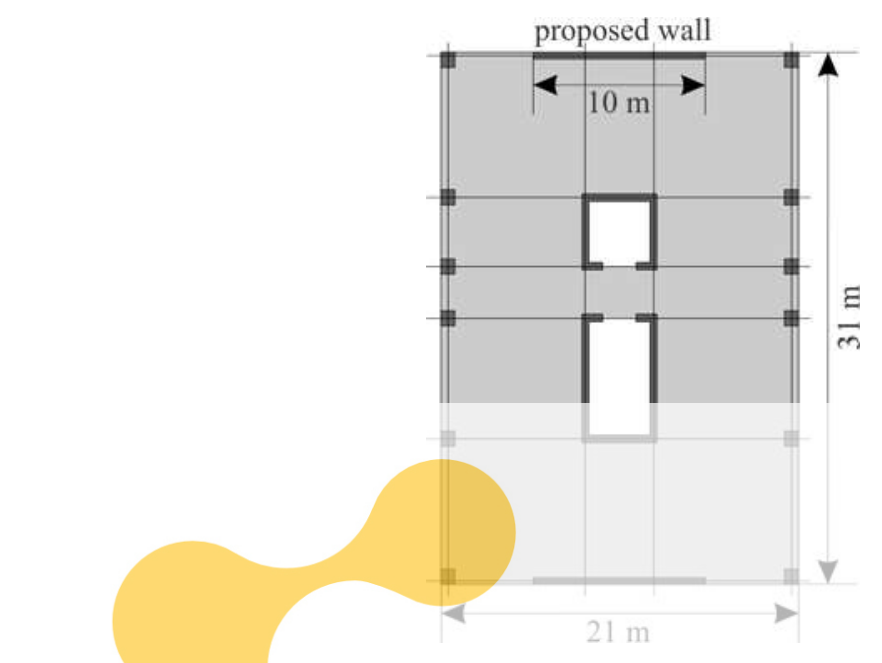

Fig. 16. Dimensions of the studied
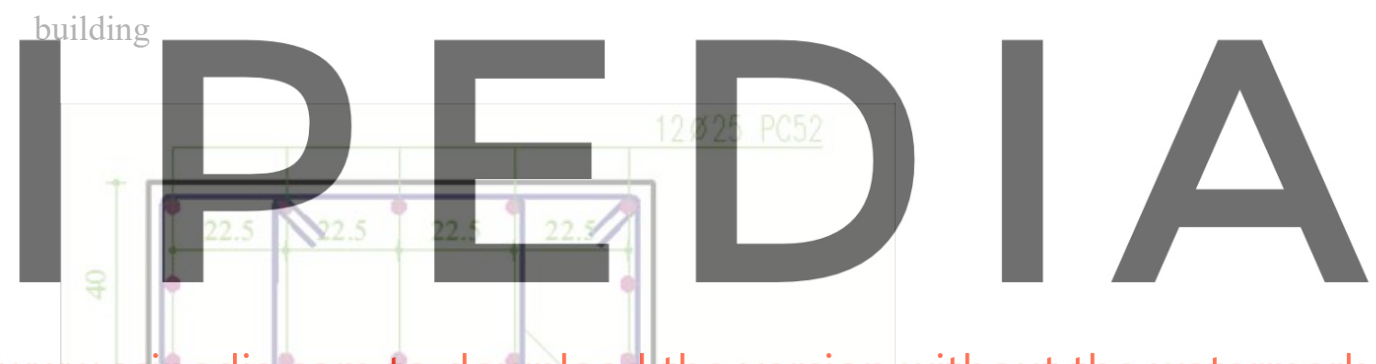

Register for free at https//www.sdipedia.com to downtoad the version without the watermark

Fig. 18. The boundary element of the RC structural wall

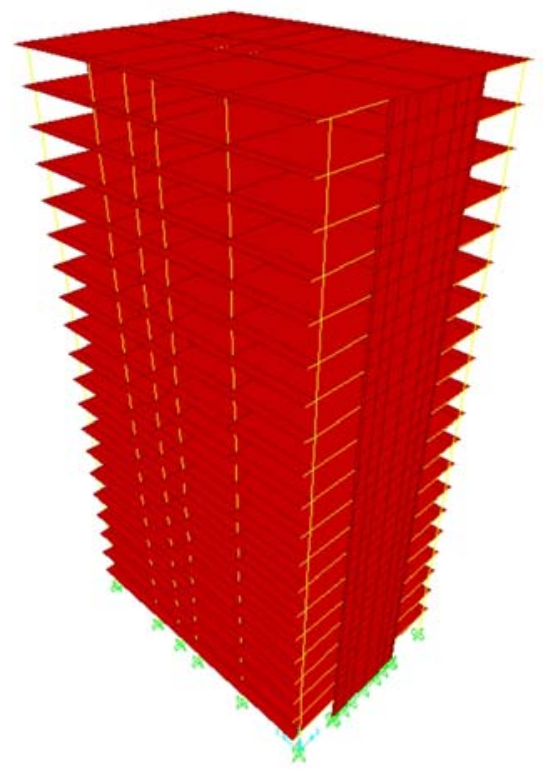


Fig. 19. The design of the dual reinforced concrete structure using the computer program SAP2000

3.2 Input ground motions for the dynamic analysis

Two records, with a different control period, were chosen for the dynamic analysis. These are the Vrancea, Romania, 1977, N-S accelerogram (Fig. 20) "(see http://www.incerc2004.ro/accelerograme.htm)", with a high predominant period of approximately $1.6 \mathrm{~s}$, and the Northridge, California, 1994 accelerogram (Fig. 21) "(see http://peer.berkeley.edu/nga/search.htm)", which has a low predominant period, of approximately $0.7 \mathrm{~s}$. Only $15 \mathrm{~s}$ of the Northridge record were considered in the analysis because of the very small time step, of $0.005 \mathrm{~s}$, used in the analysis. Thus, we tested the slit walls in two regions with different earthquake characteristics in order to study the differences which may occur regarding their failure mode, the dissipation of energy and the damage index.

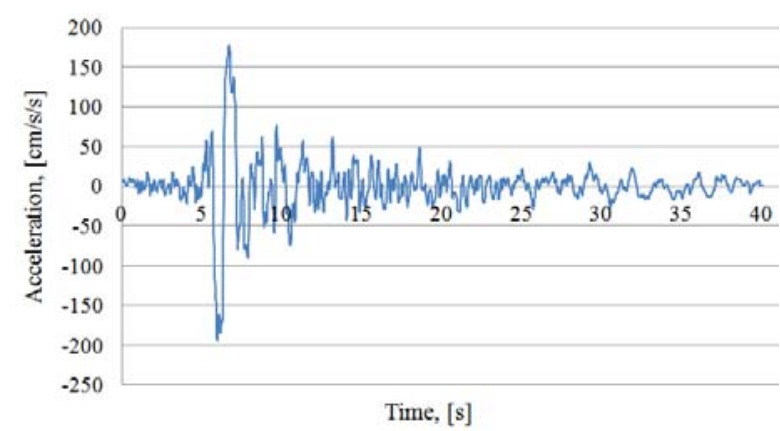

Fig. 20. Vrancea, Romania, 1977, N-S component of the acceleration

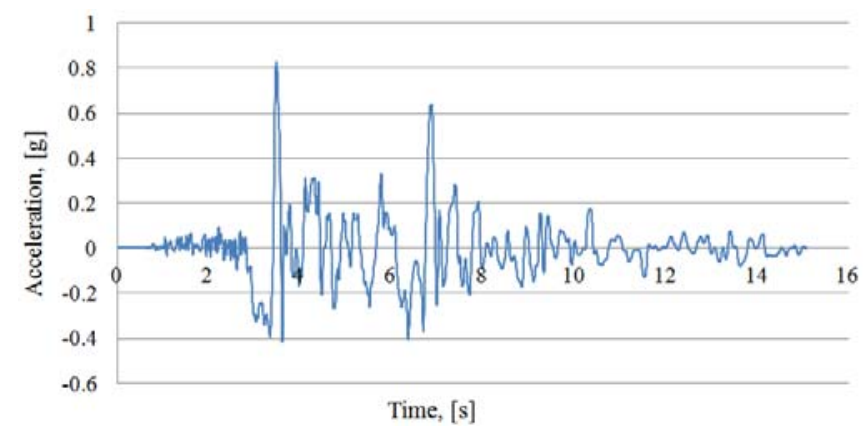

Fig. 21. Northridge, California, 1994 accelerogram

The effect of the variation of the peak ground acceleration, PGA, on the damage index, DI, was studied. In order to establish a relation between PGA and DI we performed dynamic analyses. The earthquake accelerograms used in the dynamic analysis were scaled with the PGA and for each accelerogram we calculated the structure obtaining for each PGA the maximum top displacement and the corresponding base shear. With these values an IDA (incremental dynamic analysis) curve was created (Fig. 22) [FEMA 440, 2005, Han and Chopra, 2006, Oller et al., 1996, Oller and Barbat, 2006, Faleiro et al., 2008, Faleiro et al., 2010, Vargas et al., 2013, Vargas et al., 2014]. The increase of the PGA allows capturing the behavior of the structural slit walls for both earthquakes chosen. The earthquakes were scaled from a very small value of the peak ground acceleration, for which the walls behave elastic, till big peak ground acceleration for which the connections fail and the wall splits in two parts. For the analysis with the Vrancea $1977 \mathrm{~N}-\mathrm{S}$ earthquake (INCERC Bucharest, Romania), the PGA values used in the analysis were $0.06 \mathrm{~g}, 0.1 \mathrm{~g}, 0.15 \mathrm{~g}, 0.2 \mathrm{~g}, 0.25 \mathrm{~g}$, $0.3 \mathrm{~g}, 0.35 \mathrm{~g}$ and for the analysis with Northridge 1994 earthquake (Sylmar Converter, Los Angeles, USA), the PGAs used into the analysis were $0.1 \mathrm{~g}, 0.2 \mathrm{~g}, 0.4 \mathrm{~g}, 0.6 \mathrm{~g}, 0.8 \mathrm{~g}, 1.0 \mathrm{~g}$.

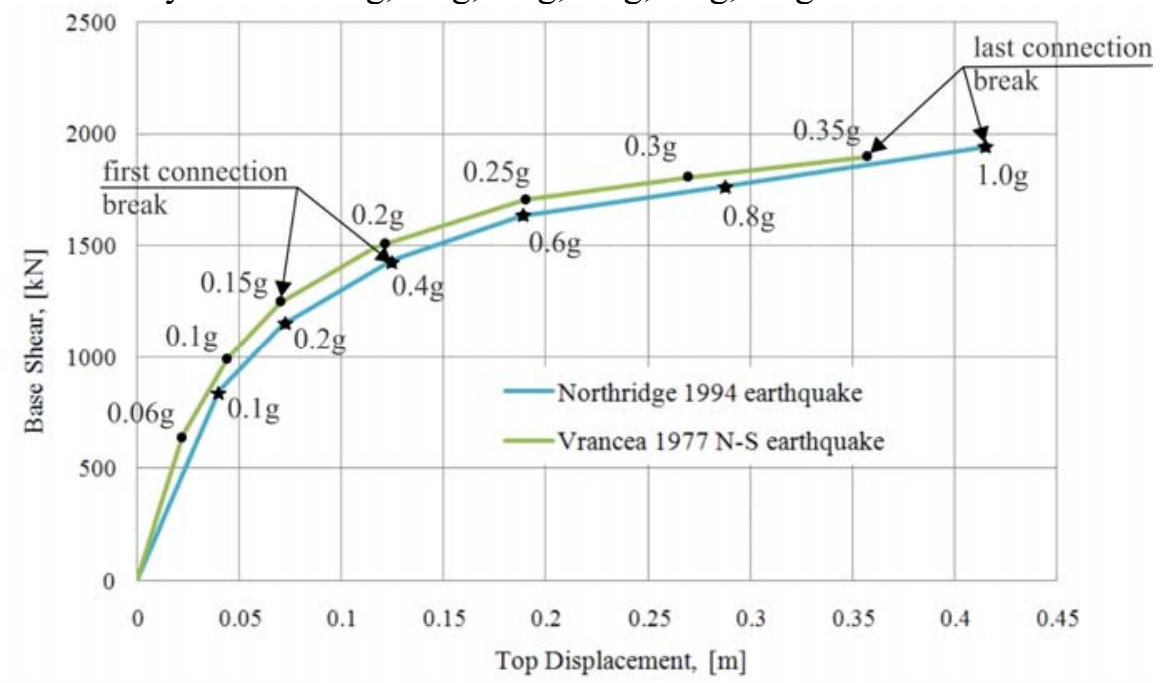

Fig. 22. Dynamic pushover curves for the slit wall for Vrancea 1977 N-S earthquake and Northridge 1994 earthquake 


\subsection{Comparative analysis of the slit and solid walls}

The comparative hysteretic behaviour of the slit and solid walls as well as the dissipated hysteretic energies, obtained by performing their dynamic analysis with the seismic accelerogram of the N-S component of the Vrancea, 1977, earthquake scaled at a PGA of 0.3g, are shown in Fig. 23 and Fig. 24, respectively. The results of the same analyses, performed with the accelerogram of the Northridge 1994 earthquake scaled at a PGA of 0.6g, are shown in Fig. 25 and Fig. 26. When the connections start to fail, the slit wall begins to dissipate more energy and the difference between the energy dissipated in the two cases increases. It is clear that before the failure of any connection, the behavior of these two walls (slit wall and solid wall) is almost identical and the dissipated energy is the same. It can be concluded that the slit wall has a higher energy dissipation capacity than the solid wall. The area enclosed by the hysteretic loop corresponds to the hysteretic energy dissipated by the walls during that earthquake and represents the amount of energy that the structure has to dissipate through inelastic nonlinear response. If the structure can dissipate the hysteretic energy demanded by the earthquake, it will survive.

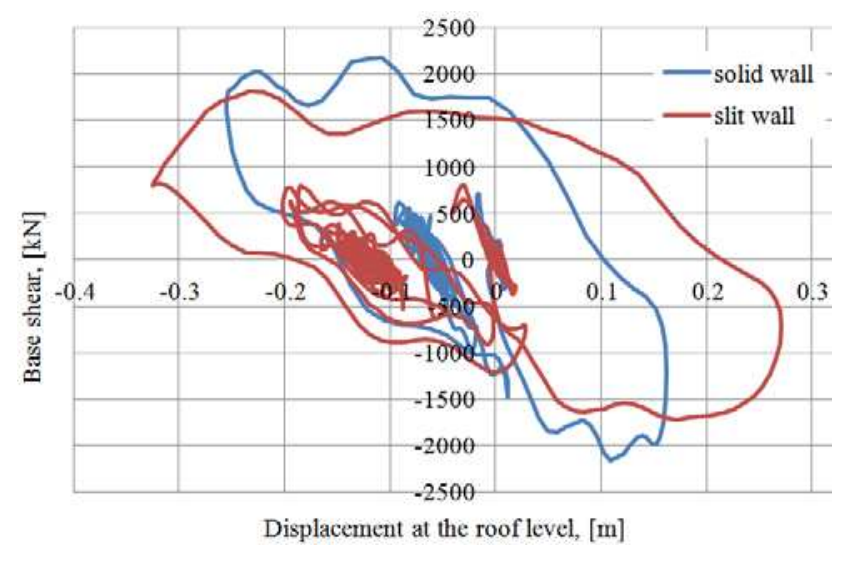

Fig. 23. Hysteretic behaviour of the walls at Vrancea $1977 \mathrm{~N}-\mathrm{S}$ earthquake, $\mathrm{PGA}=0.3 \mathrm{~g}$

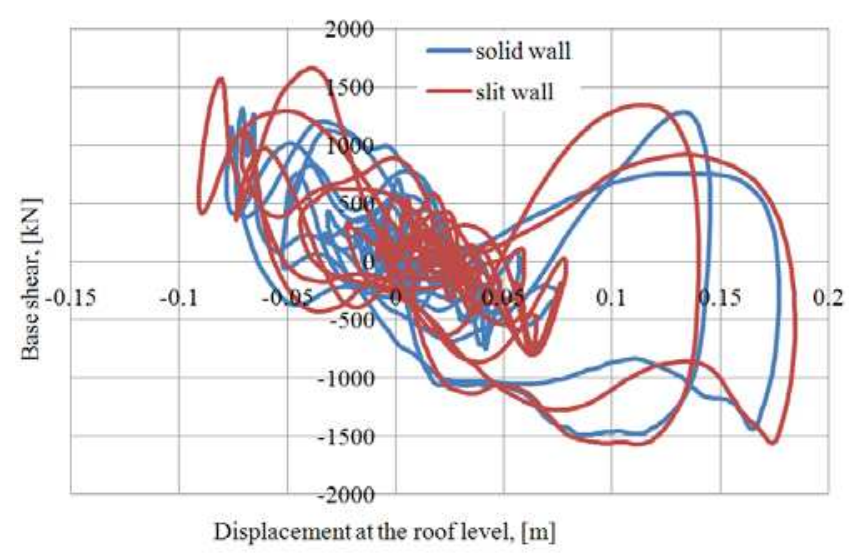

Fig. 25. Hysteretic behaviour of the walls at Northridge 1994 earthquake, PGA=0.6g

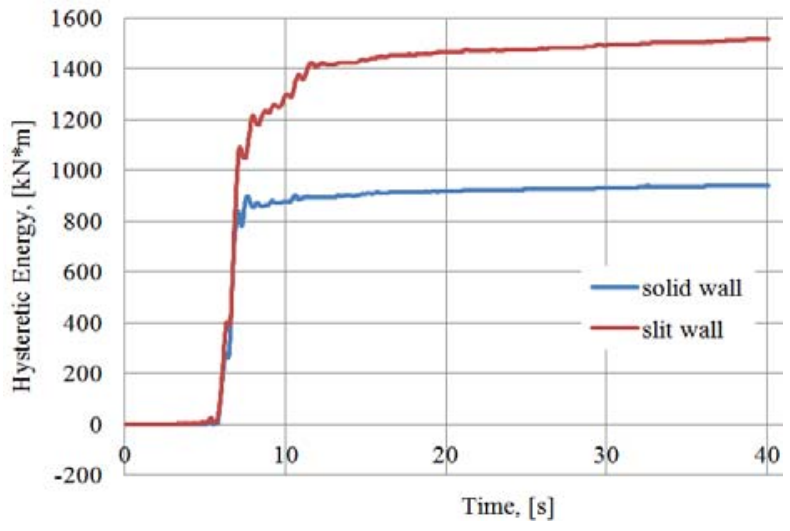

Fig. 24. Hysteretic energy dissipation of the walls at Vrancea $1977 \mathrm{~N}-\mathrm{S}$ earthquake, PGA $=0.3 \mathrm{~g}$

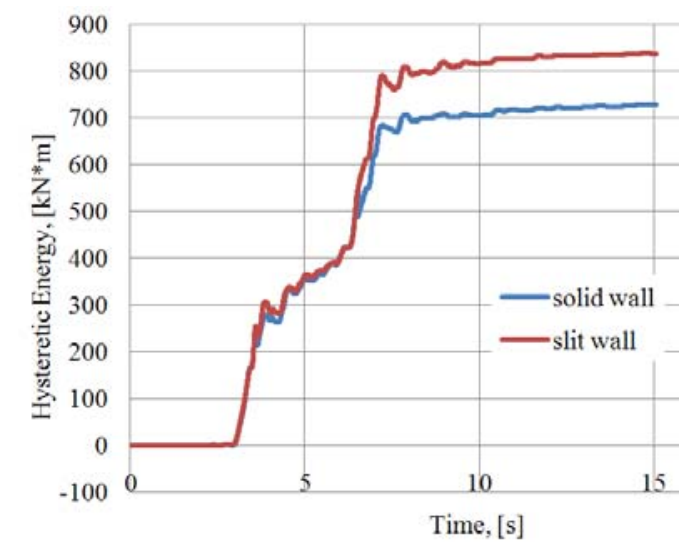

Fig. 26. Hysteretic energy dissipation of the walls at Northridge 1994 earthquake, $\mathrm{PGA}=0.6 \mathrm{~g}$

The comparison between the damage results obtained for the slit and the solid walls for both earthquakes considered in the analysis allows establishing a relationship between damage index and PGA (Fig. 27 and Fig. 31) and between the dissipated hysteretic energy and the displacement at the roof level (Fig. 28, Fig. 29, Fig. 30 and Fig. 32). The mentioned results are obtained by increasing the PGA and by scaling adequately the accelerograms for these PGA, until the collapse of the walls is reached. Two comparisons are made, one between the spectral accelerations (Fig. 33) and the other one between the displacement timehistory (Fig. 34), at the top of the studied walls subjected to the Vrancea, 1977, N-S component of the earthquake, scaled for a PGA of $0.4 \mathrm{~g}$. It is important to note that for this PGA the short connections are crushed. 


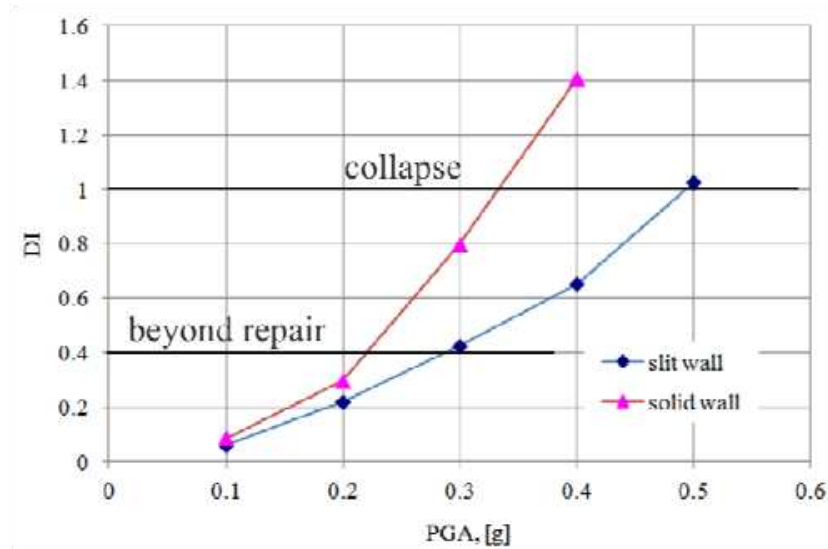

Fig. 27. The variation of DI with PGA for Vrancea 1977 N-S earthquake

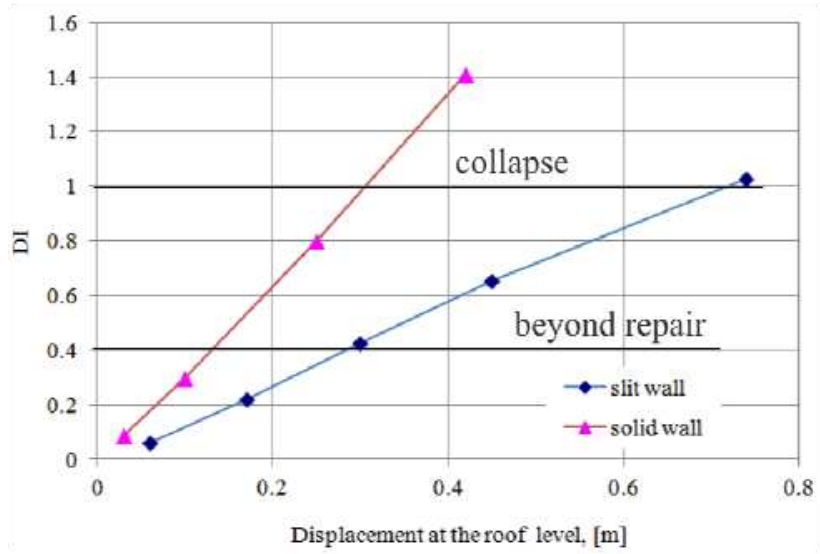

Fig. 29. The variation of DI with displacement at the roof level for Vrancea 1977 N-S earthquake

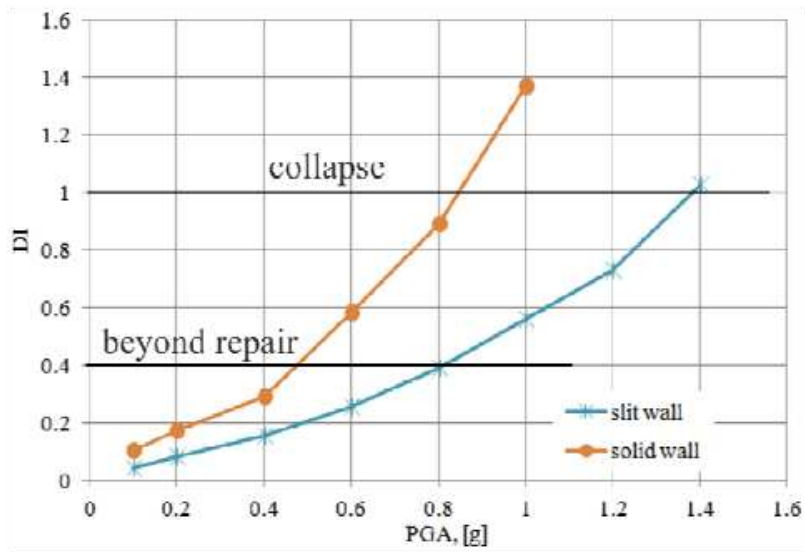

Fig. 31. The variation of DI with PGA for the Northridge 1994 earthquake

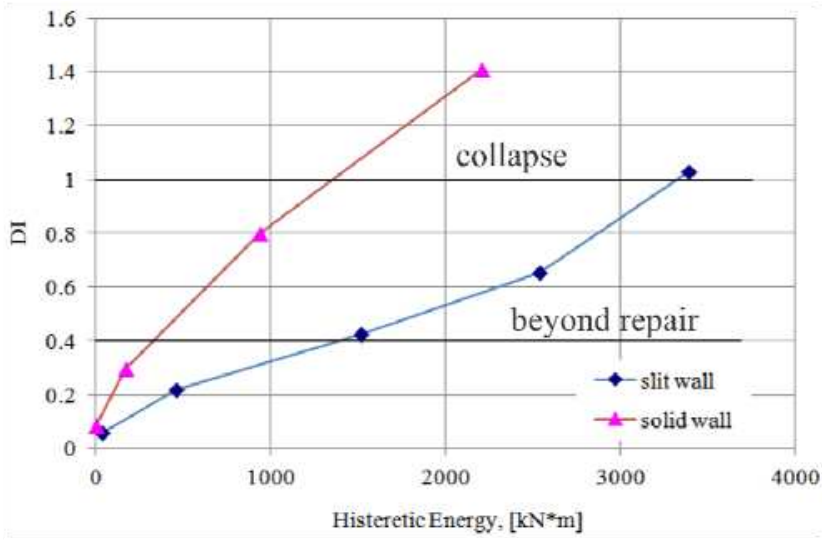

Fig. 28. The variation of DI with hysteretic energy dissipated for Vrancea 1977 N-S earthquake

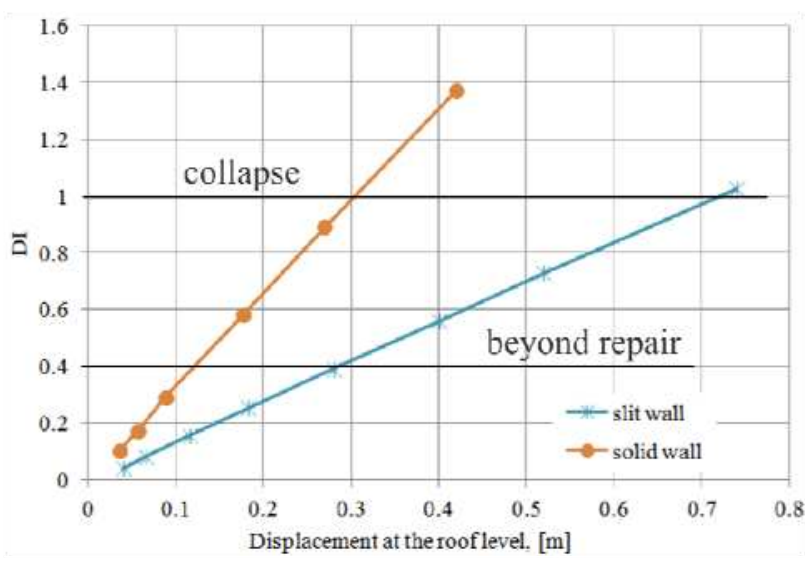

Fig. 30. The variation of DI with displacement at the roof level for Northridge 1994 earthquake

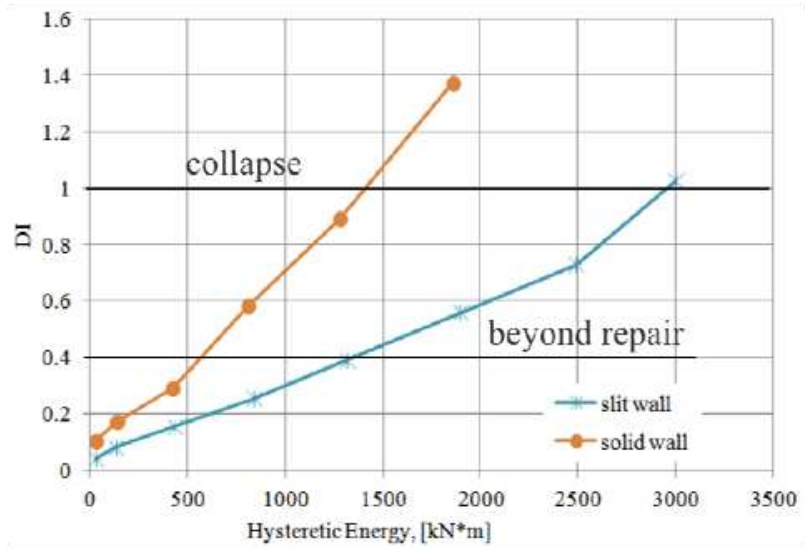

Fig. 32. The variation of DI with hysteretic energy dissipated for the Northridge 1994 earthquake 


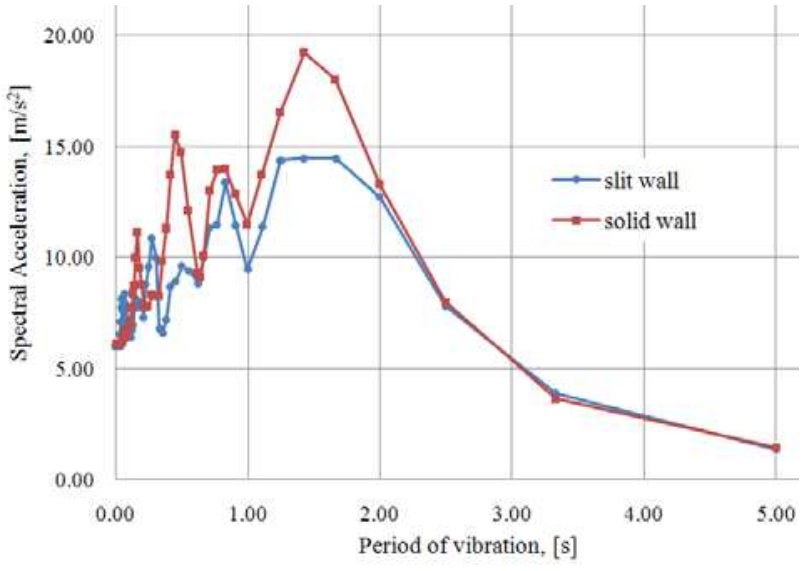

Fig. 33. Spectral acceleration of the proposed walls for the Vrancea $1977 \mathrm{~N}-\mathrm{S}$ earthquake, $\mathrm{PGA}=0.4 \mathrm{~g}$

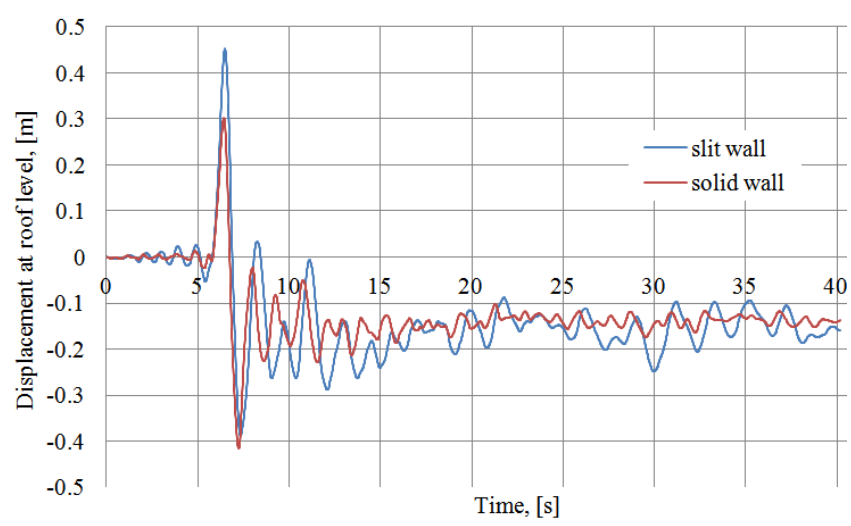

Fig. 34. The top displacement response of the proposed walls for the Vrancea 1977 N-S earthquake, $\mathrm{PGA}=0.4 \mathrm{~g}$

\section{Discussions of the results}

Performance levels describing the expected performance of the building in terms of damage level, economic losses and interruption of its functioning can be defined, given a certain level of seismic hazard. Such performance levels, or limit states, are:

- Life protection level for a infrequent of rare seismic action, by preventing collapse of the structure or parts thereof and maintaining integrity and residual load capacity,

- Property loss reduction level due to a frequent event, by limiting structural and non-structural damage.

The non-structural and structural damage limitation performance objective is achieved by limiting the overall deformations (lateral displacements) of the system to levels acceptable for integrity of all its parts. To achieve these performance levels, a structure should have a high stiffness for low intensity earthquakes and a low stiffness with high ductility for high intensity earthquakes. In agreement with the mentioned performance levels, the slit wall analyzed in this study is an ideal element for designing buildings in seismic areas, because it has high initial stiffness and low final stiffness with high ductility.

The comparisons between the two proposed structural walls reveal that they have a quite different behaviour. From the results obtained for the Vrancea, 1977, N-S earthquake, we can see in Fig. 27 that the solid wall fails before the slit wall. The solid wall fails at a PGA of approx. 0.35g and the slit wall fails at a PGA of approx. $0.5 \mathrm{~g}$. Fig. 28 shows how much hysteretic energy is dissipated by the two walls until reaching the collapse level. It is clear that the slit wall is dissipating more hysteretic energy at every level of damage. Beyond the repair level, the slit wall dissipates approx. $1500 \mathrm{kN} \times \mathrm{m}$ hysteretic energy and the solid wall dissipates only approx. $400 \mathrm{kN} \times \mathrm{m}$ hysteretic energy; at collapse level, the slit wall dissipates approx. 3500 $\mathrm{kN} \times \mathrm{m}$ hysteretic energy and the solid wall dissipates only approx. $2200 \mathrm{kN} \times \mathrm{m}$ hysteretic energy. For a value of approx. $1500 \mathrm{kN} \times \mathrm{m}$ of dissipated hysteretic energy, the slit wall crosses the repair level and the solid wall collapses.

When a short connection of the slit wall starts failing, the stiffness of the wall begins to decrease and the top displacement increases. This behaviour of the slit wall does not present a great problem because, as we can see in the Fig. 29 and Fig. 30, the damage index has low values. At the collapse level, the displacement of the slit wall is of approx. $0.7 \mathrm{~m}$ and for solid wall it is of approx. $0.3 \mathrm{~m}$ for both earthquakes considered in the analysis. It follows that, for the same displacement, the damage index is very different; for example, at a displacement of $0.3 \mathrm{~m}$, the slit wall has a DI equal to 0.4 and it is beyond the repair level while the solid wall has a DI equal to 1 and it is at collapse level. In the Fig. 29 and 30 an almost linear relation is observed between the top displacement and the DI. In order to explain this fact, we have split the Park \&Ang relation and calculated each term separately in order to see with which percent they contribute to the final value. The conclusion is that the first term $\frac{\delta_{m}}{\delta_{u}}$ has a share of $80 \%$ and the second term $\frac{\beta}{\delta_{u} P_{y}} \int d E_{h}$ has a 
share of $20 \%$. The second term is smaller because it is influenced by the $\beta=0.1$ parameter and $P_{y}$ which is the yield strength from the idealized curve $(=1900 \mathrm{kN}$ for the slit wall and $2565 \mathrm{kN}$ for the solid wall).

Analyzing Fig. 31 and Fig. 32, we can observe that the Northridge 1994 earthquake has a lower effect on the studied walls than the Vrancea 1977 N-S earthquake. This is because the Northridge 1994 earthquake has a control period of approx. $0.7 \mathrm{~s}$, that is, closer to the initial natural period of vibration of the studied walls $(0.647 \mathrm{~s}$ for solid wall and $0.715 \mathrm{~s}$ for slit wall) and, when the structural walls begin to crack and their natural periods of vibration increase, the resonance phenomenon is avoided. When increasing the natural period of vibration, the Vrancea $1977 \mathrm{~N}-\mathrm{S}$ earthquake, with a control period of approx. $1.6 \mathrm{~s}$, becomes more hazardous for the studied walls. The slit wall fails at a PGA of $0.5 \mathrm{~g}$ for the Vrancea $1977 \mathrm{~N}-\mathrm{S}$ earthquake, with a dissipated hysteretic energy of approx. $3500 \mathrm{kN} \times \mathrm{m}$, but fails at a PGA of $1.4 \mathrm{~g}$ for Northridge 1994 earthquake, with a hysteretic energy dissipated of approx. $3000 \mathrm{kN} \times \mathrm{m}$. The control period of the Northridge 1994 earthquake is near to the control period of the seismic area where the proposed building with structural walls is located.

The nonlinear response of the reinforced concrete structural walls is accompanied by a decrease of stiffness and an increase of damping up to a certain level of damage. By increasing the damping, the effects of the ground motion is reduced. After the failure of the short connections, the slit walls have a damping value greater than the solid wall. The damping increase is originated by the fact that, after the connections failure, the wall becomes more flexible. Fig. 33 also shows that after the connections failure the spectral acceleration decreases due to hysteretic damping increase and to structure period increase. As we can see in Fig. 33, the spectral acceleration of the slit wall for the Vrancea $1977 \mathrm{~N}-\mathrm{S}$ earthquake and for a PGA=0.4g has a lower values than that of the solid wall after the failure of the short connections. This means that the seismic forces are smaller for the slit wall and an economical design can be done. To capture the behaviour of the slit wall after the short connections fails, a PGA of $0.4 \mathrm{~g}$ was selected for the Vrancea $1977 \mathrm{~N}-\mathrm{S}$ earthquake. Fig. 34 shows that the short connections fail after the fifth second of the seismic ground motion, once occurred the main shock and when the behaviour of the slit wall changes. The stiffness of the slit wall decreases and the natural period increases.

\section{Conclusions}

The objective of this study was to investigate the effectiveness of the proposed slit wall solution in increasing the energy dissipation in reinforced concrete structural walls of high-rises buildings. In this article, a slit zone is inserted on the height of the structural wall and five short connections are introduced in the slit. The proposed solution changes the behaviour of the solid wall providing more ductility, energy dissipation and a better crack pattern. When the short connections behave elastically, the initial stiffness of the slit wall is close to the stiffness of the solid wall but, when the short connections begin to develop large cracks or fail, the wall stiffness decreases rapidly, without developing large cracks at the base. A nonlinear dynamic analysis of the walls has been performed by using SAP2000 and a layered model, while the short connections were simulated with a hysteretic pivot model. The static monotonic behaviour of these short connections is modelled in finite element software ANSYS 12, that is able to handle complex geometries and to describe precisely the complex stress state and the cracking pattern. The hysteretic force-displacement curve of the short connection is obtained using a series of hysteretic rules for loading and unloading. The combinations of the two software were very useful in these analyses because a simple model was created that consume low processing resources and reduces processing time for a dynamic analysis. We needed such a simple model because a dynamic pushover was done, where multiple dynamic analyses varying the PGA were performed. Using the dynamic analysis results, a damage evaluation of the walls was done by using the Park\&Ang damage index.

Comparative studies between the slit and solid walls allow concluding that:

- For the same displacement, the damage index DI is very different in the two cases; for example, at a displacement of $0.3 \mathrm{~m}$ the slit wall has a DI equal to 0.4 and is beyond the repair level while the solid wall has a DI equal to 1 and is at collapse level.

- The slit wall is dissipating more hysteretic energy than the solid wall; for example, when the slit wall is beyond the repair level, and dissipates approx. $1500 \mathrm{kN} \times \mathrm{m}$ hysteretic energy, the solid wall collapses. This occurs because the slit wall has a better hysteretic energy dissipation capacity and dissipates seismic energy by cracks extended on the entire surface of the wall and by crushing of the shear connections, while the solid wall dissipates seismic energy only by large cracks at the base of the wall. 
- The damping increases in the case of the slit wall after the failure of the short connections and the spectral acceleration is reduced, the seismic forces being thus also reduced, allowing this fact an economical design.

- After the failure of the short connections, the slit wall stiffness decreases and the natural period increases, in this way being avoided the resonance phenomenon.

\section{Acknowledgements}

This work was done with financial support from the European Union under Project EURODOC POSDRU 88/1.5./S/59410, during the six month internship at the Polytechnic University of Cataluña from Barcelona, Spain.

\section{References}

ANSYS 12 Structural Analysis Guide, 2009.

Aoyama, H. (2005), Dr. Kiyoshi Muto (1903-1989), Structural Engineering International, Vol. 1, pp. 50-52.

Băetu, S., Ciongradi, I. (2011), Nonlinear analysis models of the reinforced concrete structural walls, Proceedings of International Conference DEDUCON - Sustainable Development in Civil Engineering, Iasi, Vol. 1, pp. A66-A83.

Băetu, S., Ciongradi, I. (2012), Nonlinear finite element analysis of reinforced concrete slit walls with ANSYS (II), Bulletin of the Polytechnic Institute of Iasi, Construction and Architecture section, Vol. LVIII No. 1, pp. 99-111.

Băetu, S., Ciongradi, I., Văsieş, G. (2010), Static nonlinear analysis of structural reinforced concrete walls energy dissipaters with shear connections, "Computational Civil Engineering 2010”, International Symposium, Iasi, Romania.

Barbat, A. H., Carreño, M. L., Pujades, L. G., Lantada, N., Cardona O. D. and Marulanda, M. C. (2010), Seismic vulnerability and risk evaluation methods for urban areas. A review with application to a pilot area, Structure and Infrastructure Engineering, 6, 1-2, 2010, 17-38.

Barbat, A. H., Pujades, L. G., Lantada N. and Moreno, R. (2006), Performance of buildings under earthquakes in Barcelona, Spain, Computer-Aided Civil and Infrastructure Engineering, 21, 573-593.

Belarbi, A., Prakash, S.S. (2009), Assessment of performance-based design approach for RC bridge columns under combined loadings using damage index models, SBEIDCO - $1^{\text {st }}$ International Conference on Sustainable Built Environment Infrastructure in Developing Countries, Oran, Algeria, pp. 33-40.

Belmouden, Y., Lestuzzi, P. (2007), Analytical model for predicting nonlinear reversed cyclic behaviour of reinforced concrete structural walls, Engineering Structures, Vol. 29, pp. 1263-1276.

Bostenaru, D.M., Sandu, I. (2002), Reinforced concrete cast - in - situ shear wall buildings, Housing Report nr. 78, World Housing Encyclopedia.

Code for seismic design of buildings P100-1/2006. (in Romanian)

Code for the design of buildings with reinforced concrete structural walls CR 2-1-1.1-2005. (in Romanian)

Costa Domingues, J.L. (2006), Rigid-plastic seismic design of reinforced concrete structures, PHD Thesis, Technical University of Denmark, Department of Civil Engineering.

Dowell, R.K., Seible, F., Wilson, E.L. (1998), Pivot hysteresis model for reinforced concrete members, ACI Structural Journal, Vol. 95 No. 5, pp. 607-616.

Faleiro, J., Oller S. and Barbat, A. H. (2008), Plastic-damage seismic model for reinforced concrete frames, Computers and Structures, 86(7-8), 581-597.

Faleiro, J., Oller S. and Barbat, A. H. (2010), Plastic-damage analysis of reinforced concrete frames, Engineering Computations, 27(1), 57-83.

FEMA 440 - Improvements of nonlinear static seismic analysis procedures (2005).

Gedik, Y.H., Nakamura, H., Ueda, N., Kunieda, M. (2011), A new stirrup design considering 3-D effects in short deep beams, The twelfth East Asia-Pacific Conference on Structural Engineering and Constructions, Procedia Engineering, Vol. 14, pp. $2964-2971$.

Ghosh, S., Datta, D., Katakdhond, A.A. (2011), Estimation of the Park-Ang damage index for planar multi-storey frames using equivalent single-degree systems, Engineering Structures, Vol. 33, pp. 2509-2524.

Greeshma, S., Jaya, K.P., Annilet, S.L. (2011), Analysis of flanged Shear Wall Using ANSYS Concrete Model, International Journal for Civil and Structural Engineering, Vol. 2 No. 2, pp. 454-465.

Han, S.H., Chopra, A.K. (2006), Approximate incremental dynamic analysis using the modal pushover analysis procedure, Earthquake Engineering and Structural Dynamics, Vol. 35, pp. 1853-1873. 
Hiroswa, M., Past experimental results on reinforced concrete shear walls and analysis on them, BRI, Ministry of Construction, Japan, 1975.

http://peer.berkeley.edu/nga/search.htm

http://www.incerc2004.ro/accelerograme.htm

Kachlakev, D., Miller, T., Yim, S. (2001), Finite Element Modelling of Reinforced Concrete Structures Strengthened with frp Laminates, Final Report SPR 316, Oregon Department of Transportation, USA.

Kwan, A.K.H., Dai, H., Cheung, Y.K. (1999), Non-linear sesimic responce of reinforced concrete slit shear walls, Journal of Sound and Vibration, Vol. 226 No. 4, pp. 701-718.

Labafzadeh, M.S.R., Ziyaeifar, M. (2008), Seismic behaviour of RC dual ductility mode shear walls, The $14^{\text {th }}$ World Conference on Earthquake Engineering, Beijing, China, October 12-17.

Lepage, A., Neuman, S.L., Dragovich, J.J. (2006), Practical modelling for nonlinear seismic response of RC wall structures, 8th National Conference on Earthquake Engineering, San Francisco, California, April 18-22.

Liou, Y.W., Sheu, S. M.1998, Prediction of lateral stiffness for fully slitted RC shear wall, Journal of the Chinese Institute of Engineers, Vol. 21, pp. 221-232.

Lu, X., Huanjun, J. (2002), Nonlinear earthquake response analysis and energy calculation for seismic slit shear wall structures, Earthquake Engineering and Engineering Vibration, Vol. 1 No.2, pp. 227-237.

Lu, X., Wu, X. (2000), Study on a new shear wall system with shaking table test and finite element analysis, Earthquake Engineering and Structural Dynamics, Vol. 29, pp. 1425-1440.

Marin, M., Roman, O. (2010), Seismic hazard of Timişoara, Buletinul AGIR, No. 2-3, pp. 36-42.(in Rumanian)

Miao, Z.W., Lu, X.Z., Jiang, J.J., Ze, L.P. (2006), Nonlinear FE model for RC shear walls based on multi-layer shell element and microplane constitutive model, Computational methods in engineering and science, Hainan, China.

Muto, K., Ohmori, N., Itoh, T. (1973), Composite building structure and walls therefor, United States Patent 3736712.

Nagarajan, P., Jayadeep, U.B., Pillai, T.M.M. (2009), Application of micro truss and strut - and - tie model for analysis and design of RC structural elements, Songklankarin Journal of Science and Technology, Vol. 31 No. 6, pp. 647-653.

Oller S. and Barbat, A. H. (2006), Moment-curvature damage model for bridges subjected to seismic loads, Computer Methods in Applied Mechanics and Engineering, 195, 4490-4511.

Oller, S., Luccioni B. and Barbat, A. H. (1996), Un método de evaluación del daño sísmico en pórticos de hormigón armado, Revista internacional de métodos numéricos para cálculo y diseño en ingeniería, 12(2), 215-238.

Park, Y.J., Ang, A.H.S. (1985), Seismic damage analysis of reinforced concrete buildings, Journal of Structural Engineering, Vol. 111 No. 4, pp. 740-757.

Park, Y.J., Reinhorn, A.M., Kunnath, S.K., Seismic damage analysis of reinforced concrete buildings, Proceedings of Ninth World Conference on Earthquake Engineering, August 2-9, 1988, Tokyo-Kyoto, Japan, pp. 211-216.

Pasticier, L., Amadio, C., Fragiacomo, M. (2008), Non-linear seismic analysis and vulnerability evaluation of a masonry building by means of the SAP2000 V.10 code, Earthquake Engineering and Structural Dynamics, Vol. 37, pp. 467-485.

Pavlik, V.S., Vasionkin, A.N. (1976), Earthquake resistant building, Patent nr.512279, URSS.

Raongjant, W., Jing, M. (2008), Finite Element Analysis on Lightweight Reinforced Concrete Shear Walls with Different Web Reinforcement, The Sixth PSU Engineering Conference, pp. 61-67.

Sabouri, J., Ziyaeifar, M. (2009), Shear walls with dispersed input energy dissipation potential, Asian Journal of Civil Engineering (Building and Housing), Vol. 10 No. 5, pp. 593-609.

Sap2000 V14 Help (2009), Computers and Structures Inc., Berkeley, California, USA.

Sharifi, A., Banan, M.R. (2012), A strain-consistent approach for determination of bonds of ductility damage index for different performance levels for seismic design of RC frame members, Engineering Structures, Vol. 37, pp. 143-151.

Taucer, F.F., Spacone, E., Fillippou, F.C. (1991), A fiber beam - column element for seismic response analysis of reinforced concrete structures, Report No. UBC/EERC-91/17, University of California, Berkeley.

Terec, L., Bugnariu, T., Păstrav, M. (2010), Analiza Neliniară a Cadrelor din Beton Armat cu Pereţi Turnaţi în Situ, Romanian Journal of Materials, Vol. 40, pp. 214-221.

Valles, R.E., Reinhorn, A.M., Kunnath, S.K., Madan, A. (1996), IDARC 2D Version 4.0: A program for inelastic damage analysis of buildings, Tehnical Report NCEER-96-0010, State University of New York at Buffalo.

Vargas, Y. F., Barbat, A. H., Pujades L. G. and Hurtado, J. E. (2014), Probabilistic seismic risk evaluation of reinforced concrete buildings, Structures and Buildings (Proceedings of the Institution of Civil Engineering), http://dx.doi.org/10.1680/stbu.12.00031.

Vargas, Y. F., Pujades, L. G., Barbat A. H. and Hurtado, J. E. (2013), Capacity, fragility and damage in reinforced concrete buildings: a probabilistic approach, Bulletin of Earthquake Engineering, 11(6), 2007-2032. 
Vera Oyarzo, C. (2006), Damage evaluation in RC shear walls using the damage index of Park\&Ang, First European Conference on Earthquake Engineering and Seismology, Geneva, Switzerland.

Vielma, J.C., Barbat, A.H., Oller, S. (2008), An objective seismic damage index for the evaluation of the performance of RC buildings, The $14^{\text {th }}$ World Conference on Earthquake Engineering, Beijing, China.

Vielma, J.C., Barbat, A.H., Oller, S. (2009), Seismic performance of waffled-slabs floor buildings, Structures and Buildings (Proceedings of the Institution of Civil Engineering), Vol. 162 No. SB3, pp. 169-182.

Vielma, J.C., Barbat, A.H., Oller, S. (2010), Seismic safety of limited ductility buildings, Bulletin of Earthquake Engineering, Vol. 8 No.1, pp. 135-155.

Zhao, Z.Z., Kwan, A.K.H., He, X.G. (2004), Nonlinear finite element analysis of deep reinforced concrete coupling beams, Engineering Structures, Vol. 26, pp. 13-25. 